\title{
Effects of an Additional Liquid Based Cytology Prepate on Cytological Diagnosis in High-Risk HPV Positive, PaP Test Negative Cases
}

\author{
(D) Davut Şahin,' (1) Nermin Koç, ${ }^{2}$ (I) Meryem Akbaş'
}

${ }^{1}$ Acıbadem Health Group Pathology Laboratory, Istanbul, Turkey

${ }^{2}$ University of Health Sciences, Zeynep Kamil Women and Children Diseases Training and Research Hospital, Pathology Laboratory, Istanbul, Turkey

\begin{abstract}
Objectives: To investigate the effects of a second cytology preparation on cytological diagnosis in high-risk HPV positive and PaP smear-negative cases.

Methods: This retrospective study was conducted with 57 cases who underwent cytological evaluation and cotest in our center in 2016-2017. All of these cases were high-risk HPV positive, PaP smear-negative and had a second preparation. All preparations were re-evaluated by a cytopathologist and a pathologist. Twenty-five of the cases who had a positive diagnosis in the second preparation had a cervical biopsy.

Results: In $46(80 \%)$ of the cases, the cytological diagnosis was the same and negative in the first and second preparations. Second preparations of 11 cases (19.2\%) were positive. Twenty of 25 patients (77\%) with cervical biopsy had premalignant lesion.

Conclusion: In high-risk HPV positive and PaP smear-negative cases, patient management is different from cases where these two tests are positive together. According to our results, 19.2\% of high-risk HPV positive and PaP smear-negative cases were given positive cytological diagnosis by second cytology preparation. Biopsy results support our cytological findings. The incidence of positive cytological diagnosis increases in PaP smear with the second preparation. With this protocol, patient management changes, follow-up time and number can be reduced.
\end{abstract}

Keywords: Additional preparation; cytological diagnosis; high-risk HPV; smear.

Please cite this article as "Şahin D, Koç N, Akbaş M. Effects of an Additional Liquid Based Cytology Prepate on Cytological Diagnosis in High-Risk HPV Positive, PaP Test Negative Cases. Med Bull Sisli Etfal Hosp 2019;53(4):361-365".

$\mathrm{C}$ ervical cancer is the second most common cancer in women worldwide. While the incidence and mortality in developed countries are decreasing, it is still the most common cancer in developing countries. ${ }^{[1]}$ The most important risk factor for cervical cancer is a sexually transmitted Human Papilloma Virus (HPV). In high-grade squamous intraepithelial lesions of the cervix (HSIL) and squamous cell carcinomas, high-risk HPV positivity is reported to be 99\%. ${ }^{[2]}$ The traditional test for screening and early diagnosis of premalignant cervical lesions is the PaP smear test. It has been reported that the sensitivity of HR-HPV tests is higher than PaP smear. Thus, HR-HPV tests are more effective in primary screening. ${ }^{[3-5]}$ The determination of HPV types is becoming increasingly decisive in patient management

Address for correspondence: Nermin Koç, MD. Saglik Bilimleri Universitesi, Zeynep Kamil Kadin ve Cocuk Hastaliklari Egitim Arastirma Hastanesi, Patoloji Laboratuvari, Istanbul, Turkey

Phone: +90 5326400380 E-mail: nerminkoc@yahoo.com

Submitted Date: May 26, 2019 Accepted Date: September 02, 2019 Available Online Date: December 03, 2019

${ }^{\circ}$ Copyright 2019 by The Medical Bulletin of Sisli Etfal Hospital - Available online at www.sislietfaltip.org

This is an open access article under the CC BY-NC-ND license (http://creativecommons.org/licenses/by-nc/4.0/). 
and treatment selection. ${ }^{[3-5]}$ Some of the HR-HPV positive cases do not have premalignant or malignant lesions on PaP smear and even cervical biopsies. Thus, not only HPV tests are preferred for primary screening, it is recommended to use also PaP and HPV tests together (cotest). ${ }^{[6,3,2]} \mathrm{PaP}$ smear results are negative in $4 \%$ of the HR-HPV test positive cases. $^{[6,3]}$

According to the American Cancer Society (ACS) guideline recommendation, patient management of both HR-HPV and PaP smear-positive cases differs from those with HRHPV positive and PaP smear-negative cases. ${ }^{[7]}$ Therefore, in HR-HPV positive cases, the PaP test result is critical for determining patient management.

Today, fluid-based cytology (SBS) techniques have largely replaced conventional cytology in the preparation of cervical cytology specimens. ${ }^{[8]}$ In liquid-based cytology, a portion of the cytological sample taken from the cervix is used in the preparation, while the remaining part is stored as reserve material. ${ }^{[9]} \mathrm{It}$ is reported that the contribution of another preparation made from reserve material to the cytological diagnosis is insignificant. ${ }^{[9]}$ There are also studies reporting that the sensitivity of the PaP test increases with the preparation of SBS preparation from all of the reserve material. ${ }^{[9,10]}$ However, in this case, the advantages of doing HPV tests, cell block, immunohistochemical and molecular analyses from SBS preparation are lost. In daily routine, screening cytotechnologists or cytopathologists make a second preparation from the reserve material prepared when necessary.

In this study, the results of the preparation of an additional SBS preparation from reserve materials of HR-HPV positive and PAP smear-negative cases were investigated. To our knowledge, there is not any study in the literature on this subject.

\section{Methods}

This retrospective study was conducted in the 2016-2017 in our center with cytologic diagnosis and HPV Cotest cases. This study was approved by the local Ethics Committee (ATADEK 2019-7/12).

In our archive, the HR-HPV test was positive, PaP smear result was negative and 62 cases with the second preparation were included in this study. The first and second preparations of each case were re-evaluated by a cytopathologist (DS) and a pathologist (NK). In five cases, the initial preparations were not negative, and atypical squamous cells (ASC-US), which were of undetermined importance, were observed in them. Four of these cases had ASCUS in the second preparation, and one was negative. These five cases were excluded from this study. Hence, this study was con- ducted with 57 cases. The researchers agreed on the diagnosis of the first and second preparations of all the cases included in this study. Of these 57 cases, 26 of them had biopsies in the 2016-2019.

Cytology preparations were prepared by ThinPrep (Cytyc Corp., Boxborough, MA, USA) technique. ThinPrep 2000 automated processor was used for preparation. The reserve materials were stored in ThinPrep solution (Cytyc's ThinPrep PreservCyt medium). Aptima Panther test (Aptima ${ }^{\circledR}$ HPV 16 $18 / 45$ genotype assay) was used as an HR-HPV cotest. PaP smears were reported according to the 2016 version of the Bethesda system. Paraffin blocks prepared from the biopsies were cut to a thickness of five microns, and the preparations were stained with Hematoxylin-Eosin.

Descriptive statistical analyses were performed to interpret the results. SPSS version 10 (SPSS, Chicago, IL, USA) was used for the statistical analysis.

\section{Results}

The mean age of the patients was 38 years (range 21-65). At the time of this study, $70.000 \mathrm{PaP}$ smear tests were evaluated in our center. In the same period, the number of cotest was 3128 , the number of HR-HPV positive cotest was 535, and the number of HR-HPV negative cotest was 2593. The number of HR-HPV positive and PaP smear-negative cases was 162 and 62 of them had a second preparation (Figs. 1-3).

Cytological diagnoses given to the second preparations of the cases with negative first preparation were shown in Table 1, HR-HPV types determined in Table 2 and histopathological diagnoses of 26 cases with biopsy were shown in Table 3.

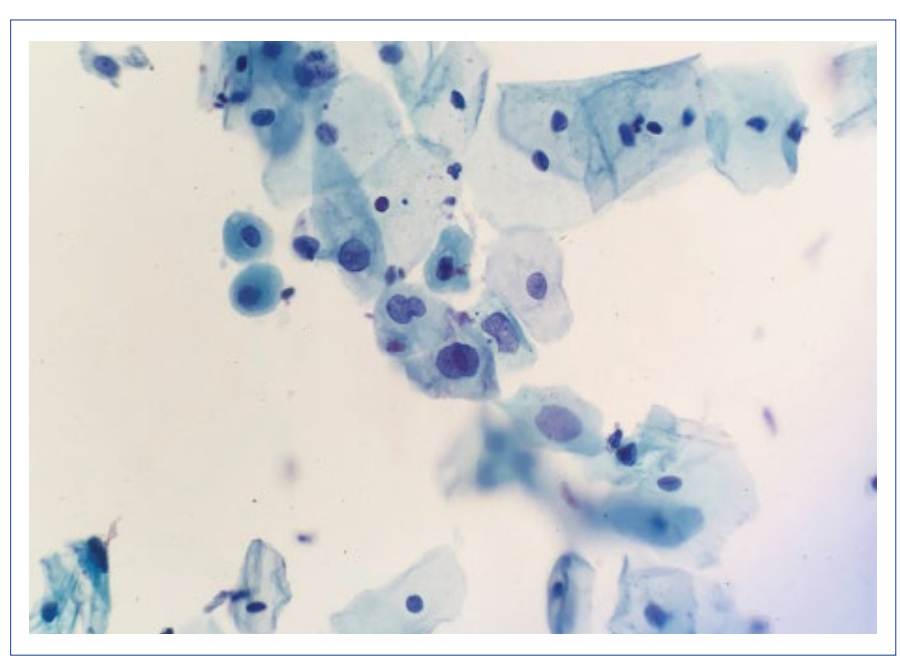

Figure 1. Second preparation of a case whose first preparation is negative. Squamous cells with a large hyperchromatic nuclei, irregular nuclear membranes, increased nucleus cytoplasm ratio; ASCUS (ThinPrep x 200). 


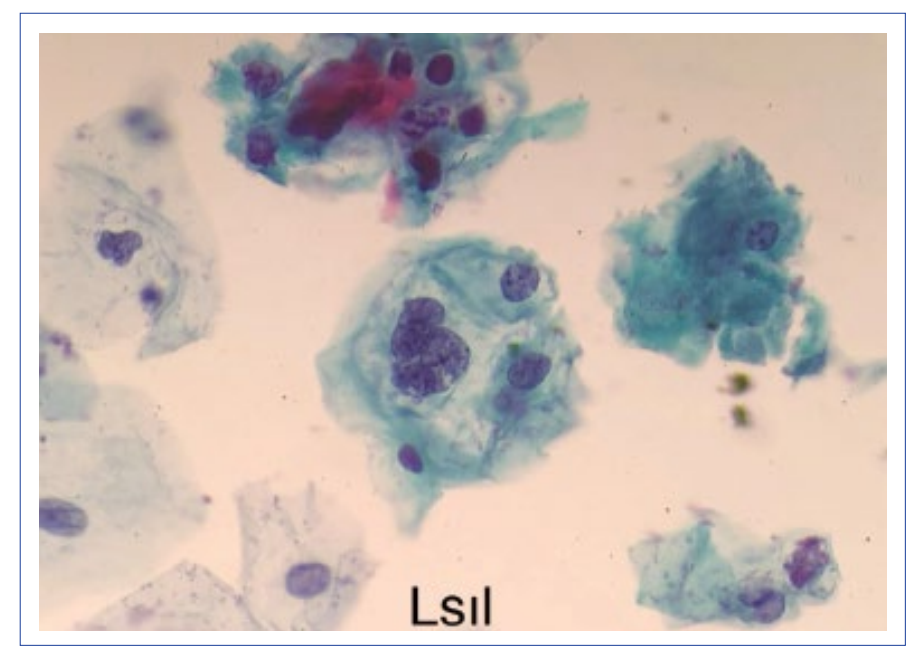

Figure 2. The second preparation of a case whose first preparation is negative. Cell with a large hyperchromatic nucleus, irregular nuclear membrane, increased nucleus cytoplasm ratio and perinuclear cytoplasmic vacuolization (koilocytosis); LSIL (ThinPrep x 400).

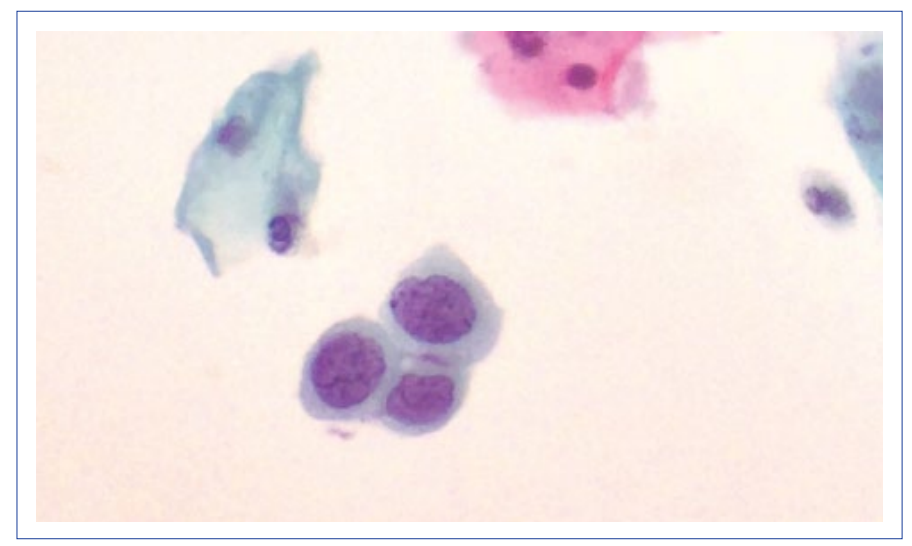

Figure 3. Parabasal-sized squamous cells with large hyperchromatic nuclei, irregular nuclear membranes and increased nucleus cytoplasm in the second preparation of the patient whose first preparation was negative; HSIL (ThinPrep x 400).

\section{Discussion}

HPV tests and PaP smear are being used together with increasing frequency for screening and early diagnosis of premalignant cervical lesions. ${ }^{[3,4]} \mathrm{PaP}$ smear is negative in some HR-HPV positive cases. ${ }^{[3,6]}$ According to the American Cancer Society (ACS) 2012 guideline proposal, in HR-HPV positive, PaP test negative cases, patient management is different from the cases with both test positive. It is recommended that women aged 20-65 years should be screened with HR-HPV and PaP test every five years or only with the PAP test every three years. Direct colposcopy is recommended for women who are positive for HR-HPV and PAP tests, whereas colposcopy is not recommended for women with HR-HPV positive and PaP test negative. A follow-up system with two options is recom-
Table 1. HR-HPV positive, PAP smear negative cases prepared by the second preparations of cytological diagnosis and rates $(n=57)$

\begin{tabular}{lcc}
\hline $\begin{array}{l}\text { Cytological diagnosis of } \\
\text { additional preparation }\end{array}$ & $\mathbf{n}$ & $\%$ \\
\hline NILM & 46 & 80 \\
ASCUS & 9 & 16 \\
LSIL & 1 & 2 \\
HSIL & 1 & 2 \\
Total & 57 & 100 \\
\hline
\end{tabular}

NILM: Negative for Intraepithelial Lesion or Malignancy; ASC-US: Atypical Squamous Cell that are Undetermined Significance; LSIL: Lowgrade Squamous Intraepithelial Lesion; HSIL: High-grade Squamous Intraepithelial Lesion.

Table 2. High-risk HPV types and rates positive in cases $(n=57)$

\begin{tabular}{lcc}
\hline HPV Type & $\mathbf{n}$ & \% \\
\hline HPV 16 & 13 & 23 \\
HPV 18/45 & 7 & 12 \\
One of the other HR types & 37 & 65 \\
\hline
\end{tabular}

HPV: Human Papilloma Virus.

Table 3. Histopathological diagnosis and rates of biopsies of highrisk HPV-positive cases who were negative for the first and positive for the second $(n=26)$

\begin{tabular}{lc}
\hline Histopathological diagnosis & $\mathbf{n}(\%)$ \\
\hline Chronic cervicitis (negative) & $6(23)$ \\
HSIL & $5(19)$ \\
LSIL & $15(58)$ \\
\hline
\end{tabular}

HPV: Human Papilloma Virus; HSIL: High-grade Squamous Intraepithelial Lesion; LSIL: Low-grade Squamous Intraepithelial Lesion.

mended for this last group. Option 1: cotest once every 12 months. Option 2: HPV 16 or HPV 16/18 genotype search. Colposcopy, if HPV 16 or HPV $16 / 18$ is positive, followed by cotest every 12 months if both are negative. ${ }^{[7]}$ Thus, $\mathrm{PaP}$ test results of HR-HPV positive cases are very critical in patient management.

Since the beginning of the 2000s, conventional cytology has been replaced by SBS techniques in the preparation of cervical smear specimens. ${ }^{\left[{ }^{111]}\right.}$ In liquid-based cytology techniques, while preparing a preparation from a portion of the sample taken from the cervix, the remaining portion is stored as reserve material. Since some of the cells critical and necessary for cytological diagnosis remain in the reserve material, their microscopic evaluation cannot be performed. Cytotechnicians or cytopathologists screen cervical cytology preparations and prepare a second preparation from the reserve material in some cases where cytomorphological features are suspicious but in- 
adequate for definitive diagnosis, cytological findings are not consistent with patient history, and cellularity and preparation quality are not optimal. A positive diagnosis is given to the second preparation of some of the negative cases in the first preparation, and in some positive cases, the diagnosis can be upgraded. It is reported that the rate of changing the cytological diagnosis of preparing an additional preparation from reserve material in cases with unknown HR-HPV result is insignificant or minimal. ${ }^{[9]}$ In a study conducted with 105 cases, 10 new preparations were prepared from the reserve material of each case and it was shown that cytologic diagnosis was upgraded in up to $14 \%$ of the cases. ${ }^{[12]}$ In our study, it can be asserted that $19.2 \%$ of HR-HPV positive and PaP smear-negative cases were given a positive diagnosis with an additional preparation. There is a strong relationship between HPV and cervical premalignant lesions and carcinomas. ${ }^{[13]}$ Therefore, it can be expected that the second SBS preparations of HR-HPV positive and PaP test negative cases would be $19.2 \%$ positive. The data obtained from 26 cases with cervical biopsy supported our cytology results. The presence of squamous intraepithelial lesions ( 15 LSIL, 5 HSIL) in $20(77 \%)$ of 26 cases on biopsy indicates that HR-HPV positive cases are a high-risk group. Our results suggest that it is necessary to prepare the second preparation in HR-HPV positive and PaP smear-negative cases and with this application, patient management can be changed in $19.2 \%$ of the cases and follow-up number and duration can be reduced. It can be said that the reserve material advantage of SBS will be lost with additional preparation. Since the HR-HPV type of the cases is determined, it is not necessary to have reserve material. It is also easy and inexpensive to obtain a cytological sample from the cervix; a new sample can be taken if additional tests and molecular analysis are required.

The limitation of this study is the small number of cases. Our results support the information that the relationship between HR-HPV and premalignant cervical lesions is very strong. It can be predicted that new studies with more cases will support our results.

\section{Conclusion}

The number of positive cytological diagnoses is increased by preparing a second liquid-based preparation in HR-HPV positive and PAP smear-negative cases. With this application, patient management changes, the number of controls decreases and the follow-up time is shortened.

\section{Disclosures}

Ethics Committee Approval: This study was approved by the local Ethics Committee (ATADEK 2019-7/12).
Peer-review: Externally peer-reviewed.

Conflict of Interest: None declared.

Authorship Contributions: Concept - D.Ş., N.K.; Design - D.Ş., M.A.; Supervision - N.Ş., D.Ş.; Materials - D.Ş., M.A.; Data collection \&/or processing - D.Ş., M.A.; Analysis and/or interpretation - D.Ş., N.K.; Literature search - D.Ş., N.K.; Writing - D.Ş., N.K.; Critical review - D.Ş., N.K.

\section{References}

1. Doğan O, Pulatoğlu Ç, Başbuğ A, Kaya AE, Yassa M. Discriminating Performance of Early Uterine and Cervical Artery Pulsatility and Resistivity In Pre-Invasive Cervical Lesions. Med Bull Sisli Etfal Hosp 2018;52:206-11. [CrossRef]

2. Ghaffari SR, Sabokbar T, Mollahajian H, Dastan J, Ramezanzadeh F, Ensani F, et al. Prevalence of human papillomavirus genotypes in women with normal and abnormal cervical cytology in Iran. Asian Pac J Cancer Prev 2006;7:529-32.

3. Schiffman M, Burk RD, Boyle S, Raine-Bennett T, Katki HA, Gage $J$, et al. A study of genotyping for management of human papillomavirus-positive, cytology-negative cervical screening results. J Clin Microbiol 2015;53:52-9. [CrossRef]

4. Carozzi F, Ronco G, Confortini M, Noferini D, Maddau C, Ciatto S, et al. Prediction of high-grade cervical intraepithelial neoplasia in cytologically normal women by human papillomavirus testing. $\mathrm{Br}$ J Cancer 2000;83:1462-7. [CrossRef]

5. Petry KU, Rinnau F, Böhmer G, Hollwitz B, Luyten A, Buttmann N, et al. Annual Papanicolaou screening for 5 years among human papillomavirus-negative women. BMC Cancer 2013;13:379. [CrossRef]

6. Kinney W, Fetterman B, Cox JT, Lorey T, Flanagan T, Castle PE. Characteristics of 44 cervical cancers diagnosed following Papnegative, high risk HPV-positive screening in routine clinical practice. Gynecol Oncol 2011;121:309-13. [CrossRef]

7. Saslow D, Solomon D, Lawson HW, Killackey M, Kulasingam SL, Cain J, et al. American Cancer Society, American Society for Colposcopy and Cervical Pathology, and American Society for Clinical Pathology screening guidelines for the prevention and early detection of cervical cancer. Am J Clin Pathol 2012;137:516-42.

8. Jeong H, Hong SR, Chae SW, Jin SY, Yoon HK, Lee J, et al. Comparison of Unsatisfactory Samples from Conventional Smear versus Liquid-Based Cytology in Uterine Cervical Cancer Screening Test. J Pathol Transl Med 2017;51:314-9. [CrossRef]

9. Massarani-Wafai R, Bakhos R, Wojcik EM, Selvaggi SM. Evaluation of cellular residue in the ThinPrep PreservCyt vial. Diagn Cytopathol 2000;23:208-12. [CrossRef]

10. Ritu N, Wilbur D. C. The Bethesda System for Reporting Cervical Cytology. Definitions, Criteria and Explanatory Notes. 3nd ed. New York: Springer ; 2014. p. xii-xv.

11. Whitlock EP, Vesco KK, Eder M, Lin JS, Senger CA, Burda BU. Liquid-based cytology and human papillomavirus testing to screen 
for cervical cancer: a systematic review for the U.S. Preventive Services Task Force. Ann Intern Med 2011;155:687-97. [CrossRef]

12. Grapsa D, loakim-Liossi A, Stergiou E, Petrakakou E, Nicolopoulou-Stamati $P$, Patsouris $E$, et al. Additional slides from residual ThinPrep Pap tests: Of potential diagnostic benefit in equivocal cases? Diagn Cytopathol 2012;40:856-60. [CrossRef]

13. Beyazit F, Silan F, Gencer M, Aydin B, Paksoy B, Unsal MA, et al. The prevelance of human papillomavirus (HPV) genotypes detected by PCR in women with normal and abnormal cervico-vaginal cytology. Ginekol Pol 2018;89:62-7. [CrossRef] 